\title{
Membrane Distillation
}

\author{
M. Saravanan Kumar \\ Department of chemical engineering Rajalakshmi Engineering College, Thandalam, Chennai, India \\ saravanan.m.2019.chem@ rajalakshmi.edu.in
}

\begin{abstract}
Membrane distillation (MD) is a recent and unique separation Technology, in use in the process industry. The process of separation in MD involves the simultaneous heat and mass transfer through a hydrophobic semi Permeable membrane, using thermal energy. Consequently a separation of the Feed solution into two components - the permeate or product and the retentate or the return stream occurs. MD utilises low grade or alternative energy, $e$. g., solar energy, geothermal energy, etc., as a source and is the most cost effective separation technology. Hence the process has come to acquire the attention and Interest of researchers, experimentalists and theoreticians all over the world. This article is a comprehensive review of the field of MD technology, including its basic principle, MD configurations, area of Applications, membrane characteristics and modules, experimental studies involving the effect of main operating parameters, MD energy and economic, application, Recent developments and innovations in hybrid MD systems.
\end{abstract}

Keywords: membrane distillation; MD; MD configurations; membrane Modules; parameters effecting MD; MD energy and economic

\section{Introduction}

Membrane distillation (MD) is a separation process where a micro - porous hydrophobic membrane separates two aqueous solutions at different temperatures. The hydrophobicity of the membrane prevents mass transfer of the liquid, whereby a gas - liquid interface is created. Desalination technology has been a source of pure water for centuries. Researches in the Field have been constantly creating more energy efficient and cost effective methods. Among the recent technologies, membrane distillation (MD) has the advantage of Performing at moderate temperatures and pressure. The MD is a thermally driven separation process and it is economical in terms of energy, since the Heat source for the process can be solar energy and also energy is recovered continuously during the process of MD, a hot saline is brought In contact with a hydrophobic membrane, which selectively allows water vapour to diffuse through, restricting the flow of liquid and hence, dissolved salts through its pores. The mass transfer of water vapour through membrane pores is driven by the vapour Pressure difference, as well as the temperature difference between the two sides of the Hydrophobic membrane, i. e., the feed side and the permeate side. MD is innovative because it brings together the key components of conventional distillation and other membrane separation processes such as Multistage flash (MSF) and reverse osmosis (RO). Besides being an economical, energy Efficient and eco - friendly process.

\section{Characteristics of MD make it promising: -}

- Compact process size,

- Theoretically, it promises $100 \%$ rejection of ions, macromolecules, colloids, Biological cells and other non - volatile impurities,

- Operating temperatures considerably below boiling (varies in the range of $30^{\circ} \mathrm{C}-90^{\circ} \mathrm{C}$ ) allows the process to take advantage of low - grade waste heat, unlike Conventional distillation,

- The membrane and the process solution interact less,

- MD is less demanding of the membrane's mechanical strength,

- Lower operating pressure than pressure - driven processes (atmospheric to a few hundreds of $\mathrm{kPa}$ ),
- Alternative energy sources such as solar, wave or geothermal could be used to drive the process

- MD process suffers less fouling due to its relatively large pore size required Compared to the conventional membrane separation processes such as RO.

The general scheme of MD process

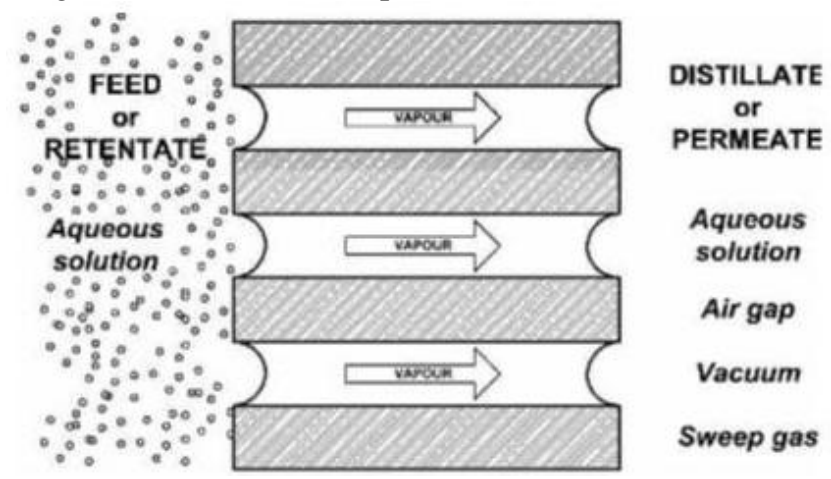

Principles of MD process:

- The membrane should be highly hydrophobic and highly porous

- Membrane not wetted by process liquids

- No capillary condensation inside the membrane pores

- Exclusive transport of vapours through membrane pores

- Vapour - liquid equilibrium of process liquid components should not be altered by the Membrane

- Direct contact of at least one side of the membrane with process liquids

- Driving force for each component is the partial pressure gradient in the vapour phase.

\section{Types of MD techniques:}

- Direct Contact MD (DCMD)

- Air Gap MD (AGMD)

- Vacuum MD (VMD)

- Sweeping Gas MD (SWGMD)

- Vacuum multi - effect membrane distillation (V MEMD)

- Permeate Gap MD (PGMD) 


\section{Configuration}

\section{Direct contact membrane distillation}

A direct contact membrane distillation (DCMD) process is characterised by a Micro - porous membrane separating the two chambers of MD, one side having the feed Water, while the other side has permeate and the cooling liquid, both in direct contact With the membrane. There is a liquid vapour interface on either side of the membrane, And only vapour from the feed side passes through the membrane to the permeate side, Where it condenses to form the output. A higher temperature on the feed water side Compared to permeate side is the driving force, which enables the vapour to cross the Membrane. Membrane being the sole barrier in this case; direct contact means that Both the feed water and the permeate are in direct contact with the membrane in the chambers.

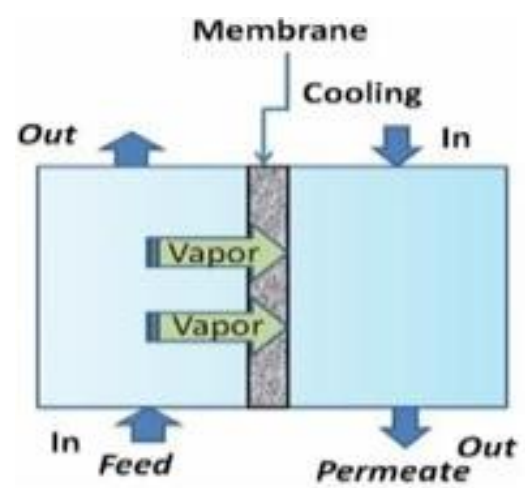

\section{Air Gap Membrane Distillation}

The mechanism of air gap membrane distillation AGMD Configuration was first proposed by Carlsson (1983), and as the name suggests is characterised by the presence of an air gap, on one side of the membrane. In AGMD, only the feed solution is in direct contact with the membrane, while on the permeate side, an air gap is introduced, separating the cooling chamber from the membrane. Thus in AGMD, the permeate is condensed on a cooler surface, compared to DCMD, which also alleviates the loss of heat energy by conduction through the membrane. The vapour Molecules crossing to the permeate side of membrane emerge out of the membrane pores, travel across the air gap, and condense on the plate. The condensed liquid is drained out of the base of the air gap by gravity. The air gap provides an additional resistance to mass transfer in AGMD, which on one hand is the major drawback of the configuration. On the other hand, it enables the process to be also used for the separation of volatile compounds, such as alcohol from aqueous solution. The wetting probability is much lower in AGMD also due to the absence of direct contact between membrane and Permeate side due to presence of the air gap. Hence, the risk of wetting on the permeate Side is much reduced. The width of air gap being much more than that of membrane, Added to the lower heat conductivity of air, then the passage of vapour across the air gap Becomes the determining step of the process. AGMD has a capability of recovering the latent heat of vaporisation, and has much higher thermal energy efficiency compared to DCMD.

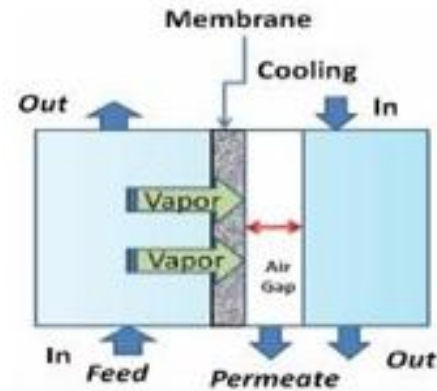

\section{Sweep gas membrane distillation}

Sweep gas membrane distillation (SGMD), also referred to as air stripping $\mathrm{MD}$, is based on the mechanism of removal of permeate by a flow of sweeping gas and its subsequent condensation done externally. SGMD was first employed for water Desalination by Basini et al. (1987). In AGMD, air is blown into the cooling chamber and onto the membrane surface tangentially, instead of keeping a still air cooling air gap between the membrane and cooling chambers, as in AGMD. Like AGMD, the flowing air removes volatile impurities from the solution, it further has the advantage of offering least resistance to the passage of vapour through it. However, the sweeping gas dilutes the permeate vapour, and this leads to more stress on the condenser, both in Terms of capacity and in energy consumption, which is a major limitation of SGMD.

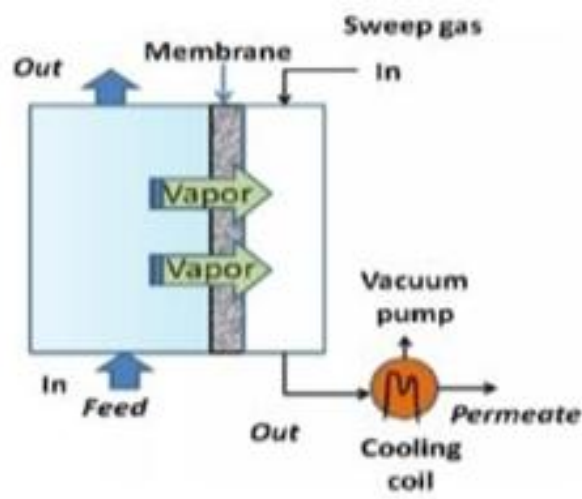

\section{Vacuum membrane distillation}

Vacuum membrane distillation (VMD) is an improvisation on SGMD, wherein instead of the mixture of sweeping gas and the permeate vapour, the vapour itself is removed alone by vacuum pump, and is subsequently condensed externally. The mechanism of the VMD, The mechanism makes the method appropriate for separation of various volatile compounds from their aqueous solutions or a mixture of the same. It is only recently that it was applied for Seawater desalination and treatment of RO brines. Here, the feed solution is Maintained at a pressure lower than the minimum entry pressure (LEP), when in contact With membrane. On the other side, the permeate is also maintained at a lower pressure Than the equilibrium vapour pressure using a vacuum pump. This enables a VMD process to achieve the best performance in terms of flux compared to other MD configurations. 


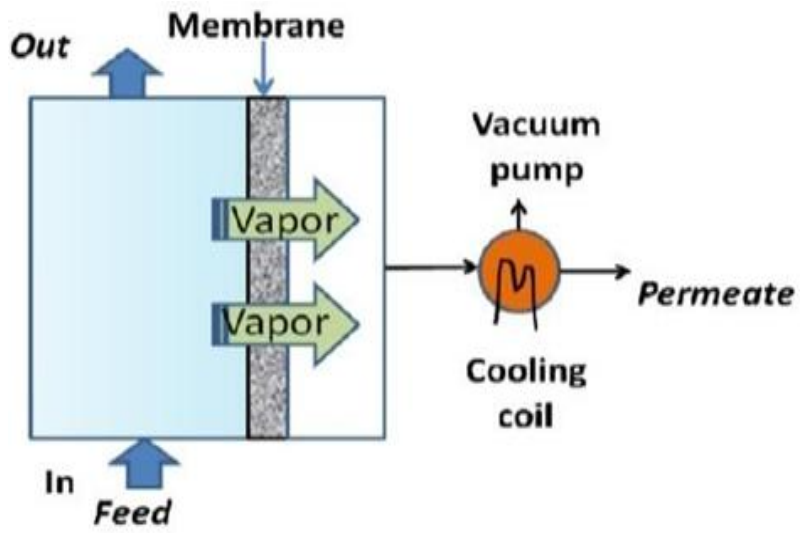

\section{MD membrane characteristics}

MD membranes should have such characteristics to show their best performance in MD process. MD membrane characterization techniques are as follows:

- Liquid Entry Pressure (LEP),

- Porosity,

- Thermal Conductivity,

- Water Contact Angle,

- Membrane Thickness.

\begin{tabular}{|c|c|c|c|}
\hline MD configuration & Application & Advantages & Disadvantages \\
\hline $\begin{array}{l}\text { Direct contact } \\
\text { membrane distillation }\end{array}$ & $\begin{array}{l}\text { *Seawater desalination } \\
\text { *crystallization } \\
\text { *Treatment of dye effluents } \\
\text { * removal from aqueous solution }\end{array}$ & $\begin{array}{l}\text { *High permeate flux } \\
\text { *Considered at commercial scale }\end{array}$ & *High conductive heat loss \\
\hline $\begin{array}{l}\text { Vacuum membrane } \\
\text { distillation }\end{array}$ & $\begin{array}{l}\text { *Seawater desalination } \\
\text { *Treatment of alcoholic solution } \\
\text { *Recovery of aroma compounds } \\
\text { *Treatment of textile wastewaters }\end{array}$ & $\begin{array}{l}\text { *High permeate flux } \\
{ }^{*} \text { Considered at commercial scale }\end{array}$ & $\begin{array}{l}\text { *High risk of membrane pore } \\
\text { wetting } \\
\text { *Process complexity }\end{array}$ \\
\hline $\begin{array}{l}\text { Air gap membrane } \\
\text { distillation }\end{array}$ & $\begin{array}{l}\text { *Seawater desalination } \\
\text { *Concentration of fruit juices } \\
\text { *Separation of azeotropic mixtures } \\
\text { *VOC removal }\end{array}$ & $\begin{array}{l}\text { *Low conductive heat loss } \\
\text { *Process simplicity } \\
\text { *Low risk of temperature } \\
\text { polarization (TP) }\end{array}$ & *Lower flux than DCMD and VM \\
\hline $\begin{array}{l}\text { Sweeping gas } \\
\text { membrane distillation }\end{array}$ & $\begin{array}{l}\text { *Brackish water desalination } \\
\text { *Separation of azeotropic mixtures } \\
\text { *Wastewater treatment } \\
\text { *VOC removal }\end{array}$ & $\begin{array}{l}\text { *Reduction of the barrier to the mass } \\
\text { transport through forced flow }\end{array}$ & $\begin{array}{l}\text { *High risk of temperature } \\
\text { polarization (TP) } \\
\text { *Process complexity }\end{array}$ \\
\hline
\end{tabular}

\section{Membrane modules}

MD processes have used a large variety of Membrane modules are one of the most important parts of MD process which control the operation parameters. Different types of MD module are manufactured so far especially for each kind of MD configurations. MD module must possess required characteristics such as high packing density; high mechanical strength and chemical and thermal stability; low pressure drop; low heat loss; and user - friendly (for cleaning or membrane replacement). MD modules are divided into three major groups including plate and frame, spiral wound, and capillary. Plate and frame module is the simplest one among all MD modules. It consists of a series of flat sheet membranes, spacers, and supports which are connected in axial direction. This type of MD module has shown good potential for commercialization due to its tangential flow in which the liquid stream is in direct contact with the membrane surface.

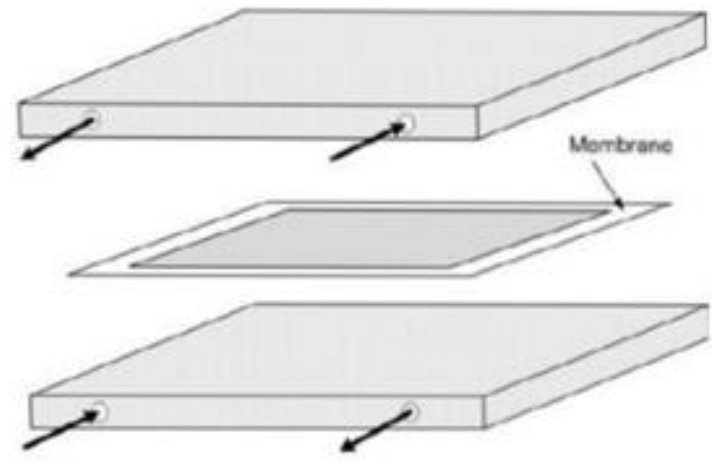

In spiral wound module, supported or unsupported flat sheet membranes are wrapped around a central tube in a spiral formation. Spiral wound module can provide tangential flow and represent high surface to volume ratio which makes it the desirable choice for applying in MD process. 


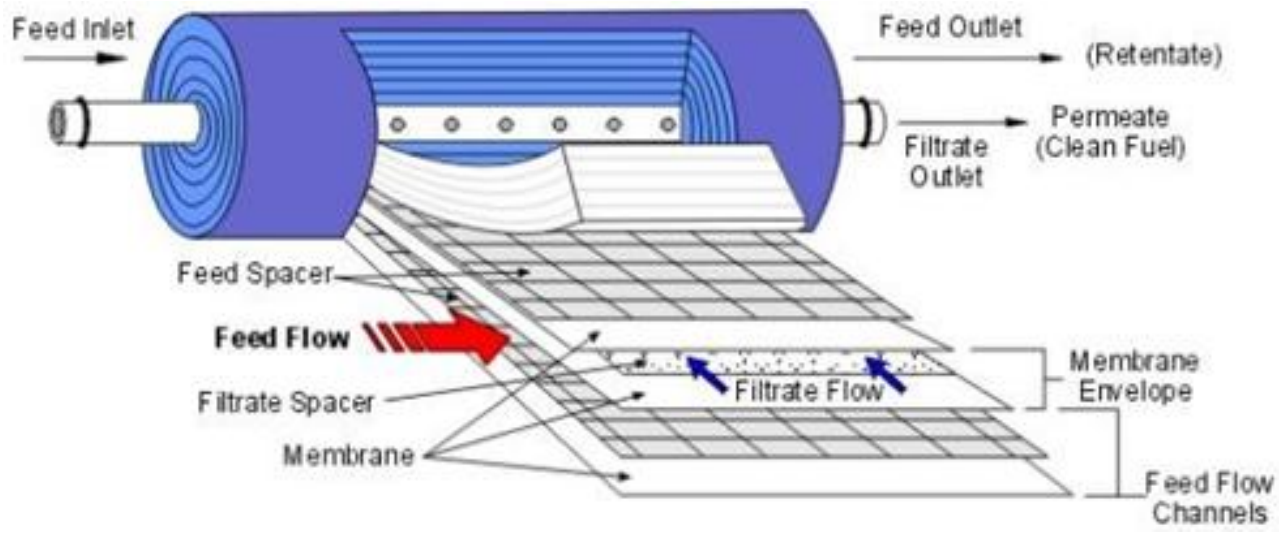

Capillary modules are divided into three main categories: (1) capillary modules, (2) tubular modules, and (3) hollow fiber modules. Capillary, tubular, and hollow fiber membranes are distinguished by their inner and outer diameter which effects on their packing density.

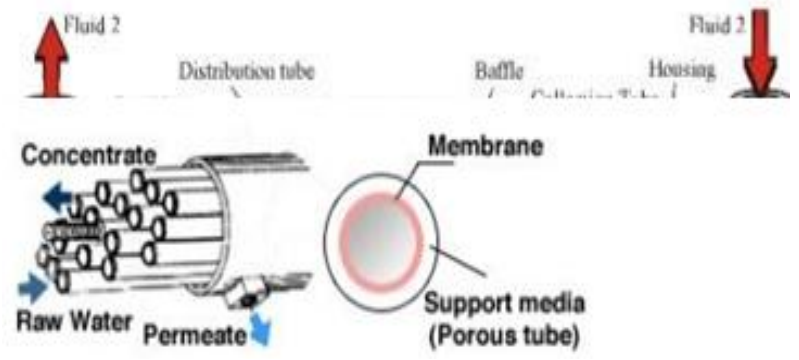

Experimental study on MD: -

- Effect of feed temperature

- Effect of feed flow rate

- Effect of concentration

- Effect of coolant permeate temperature

- Effect of temperature difference and mean temperature

- Effect of permeate flow velocity.

\section{Economics and energy consumption in MD}

MD process requires an energy source for heating the feed to a specific temperature. The ability of coupling with renewable energy sources such as solar and geothermal energy or industrial waste heat converts MD from expensive laboratory scale process to beneficial industrial one. So, especially in desalination, the water production cost (WPC) will decrease by applying a low - cost energy source. It is worth mentioning that current seawater desalination capacity is about 27 million m3/day which only meets $3 \%$ of freshwater demand. In fact, WPCs for industrial units are less than $74.39 \mathrm{inr} / \mathrm{m} 3$, whereas it may vary between $74.39 \mathrm{inr} / \mathrm{m} 3$ and $3 / \mathrm{m} 3$ small - scale units. While solar energy - based processes are typically expensive due to the high capital cost, they could slowly become competitive with conventional energy sources in the future. It must be noted that even though the WPCs of solar - powered MD (SPMD) are considerably high, it could be an interesting alternative for water production in remote areas.

Generally, lower energy consumption or using low - cost energy sources would reduce the WPC. Table summarizes energy consumption of different separation processes.

\begin{tabular}{|c|c|c|}
\hline Separation process & Production rate & Energy consumption \\
\hline RO standard & $105,000 \mathrm{~m}^{3} /$ day & 4.5 \\
\hline SPMD & $5.27 \mathrm{l} / \mathrm{m}^{2} \mathrm{~h}$ & $200-300$ \\
\hline AGMD & $5.21 / \mathrm{m}^{2} \mathrm{~h}$ & 1 \\
\hline VMD & $0.711 / \mathrm{m}^{2} \mathrm{~h}$ & 3.2 \\
\hline $\begin{array}{c}\text { Brackish water RO with } \\
\text { photovoltaic panels }\end{array}$ & $0.2 \mathrm{~m}^{3} /$ day & 1.3 \\
\hline Solar stills & $2-611 / \mathrm{m}^{2}$ day & 640 \\
\hline
\end{tabular}

\section{Application:}

MD is going to be an attractive technology for separation processes due to its unique properties. Dealing with water as a key component of chemical and physical processes and high separation factor are the most attractive characteristics of MD technology. Nowadays, MD is used in environmental, food, pharmaceutical, and nanotechnology industries. Also, MD can be used as a single - step process or can be combined with other separation techniques as a last stage. Some applications of MD are the following: Desalination of seawater, brackish water, groundwater, and brines brought from other units.

Industrial wastewater treatment including radioactive waste treatment, concentration of non - volatile acids, volatile acid recovery from industrial effluents, salt recovery by membrane distillation crystallization (MDC), and textile industry effluents. Preparation of distilled water, pure water, and ultrapure water for medical and pharmaceutical purposes. Production of liquid food concentrates such as mandarin juice, sucrose solution, whey, and apple juice. Volatiles removal from fruit juice, alcohols, halogenated VOCs, and benzene by VMD and SGMD. Dealcoholization of fermented beverages and enhanced ethanol production using DCMD. The most important MD application is desalination of wastewaters including high percentage of salt molecules in order for safe discharge into the environment or to produce drinkable, pure, and ultrapure water. The theoretical $100 \%$ rejection of non - volatile solutes, colloids, and biological matters by MD guarantees the elimination of all unwanted solutes that are often existing in water sources.

\section{Recent developments and innovations in hybrid MD} systems:

MD can be combined with other membrane technologies such as RO, microfiltration (MF), and Nano filtration (NF) as well as common distillation systems (i. e., multistage flash (MSF)) and low - cost energy sources. These hybrid systems will offer high - quality products and lower energy consumption both in the system installation and the 
discharging concentrated brine. In fact, MD hybrid systems are beneficial if they can rectify other system disadvantages. Generally, MD hybrid systems can be divided into two major groups: (i) integrated MD systems with membrane processes and (ii) integrated MD systems with other processes. The combination of MD with ultrafiltration (UF) for treatment of oily wastewater.

DCMD was applied as final purification technique after UF. The hot UF permeate entered into the DCMD cell linked in parallel form. The MD permeate is collected outside the chamber, and the oil concentrate is returned to the UF modules as feed. The product collected from the UF module commonly contains less than $5 \mathrm{ppm}$ of oil. An additional distillation process over the UF permeate leads to a complete elimination of oil from wastewater with a high removal percentage of $99.9 \%$ for total dissolved solids. As an another hybrid system, MD was integrated with RO for desalination. $\mathrm{MD}$ was suggested to desalinate $\mathrm{RO}$ brine $(75 \mathrm{~g} / \mathrm{l})$ at a temperature of $35^{\circ} \mathrm{C}$ to improve both efficiency and water recovery. Since MD is less sensitive to brine concentration than RO, more potable water can be obtained by RO/MD hybrid system. The results showed that the recovery factor of hybrid system was about $87 \%$ which was higher than that of MD (77\%) and RO (40\%). There are also some reports about using NF/MD and PV/MF/MD hybrid systems to produce high - quality products. As stated earlier, MD can be integrated with other chemical and physical separation processes. Studied the performance of hybrid bioreactor/MD system to produce ethanol. The fermentation of sugar with Saccharomyces cerevisiae (commonly known as baker's yeast) results in the formation of by - products, which can be eliminated by MD. This integration leads to improve the efficiency of sugar conversion to ethanol. The results of the fermentation tests with and without integration with MD process corroborated the advantages of the fermentation carried out with continuous elimination of fermented products by the MD module. One of the interesting characteristics of MD process is its flexibility to use renewable energy source such as nuclear power and solar energy for heating the feed solution, the possibility of nuclear desalination by DCMD coupled with a nuclear reactor. The results of experiments confirmed the feasibility of water desalination by consuming the heat and electricity generated in nuclear power plant. From the stated examples of MD hybrid systems, it is clear that all of the experiment was in laboratory or pilot scale. So, more experiment must be performed in order to remove the obstacles from commercialization of MD hybrid systems.

\section{Conclusion}

MD is a novel separation and purification process that promises numerous advantages. MD uses a hydrophobic or non - wetting, micro - porous membrane for separation. One side Of the membrane is occupied by the liquid feed phase while on the other side the pure Distillate condenses. The main separation parameters for the process are feed temperature, Vapour pressure, and concentration of feed, specifically salt concentration in case of Desalination. The unique feature of MD is that the driving force is temperature rather than Pressure, as in other membrane separation techniques. Hydrophobicity of the membrane Ensures the passage of water vapour only, restricting the entry of water completely.

The Feed water does not require any pre - treatment in this method even for highly concentrated solutions and the high standards of distillate are obtained. However the theoretical and experimental analysis of diffusion principle using Mathematical models needs to be studied further. In depth studies of temperature and Concentration polarisation on partial pressure of water vapour in membrane pores and on Flux levels and the thermodynamic equilibrium relations of the unsaturated solution in the Interface of membrane pores needs to be further studied. Furthermore, high requirements on the membrane material and membrane module must be satisfied in the applications of MD process to energy transformation. With the development of membrane materials and Their manufacturing techniques, membrane materials and membrane modules with high Performance cost ratio will be more specialised for various applications. In addition, MD Will also be applied to more multi - field studies of different industries. Energy and economy studies in MD are discussed in this article with respect to Various configurations of MD. This article is a review paper for the MD process where The types of MD, membrane characteristics and its modules, experimental studies and the Effect of operation parameters, energy economy, application and Recent developments and innovations in hybrid MD systems were discussed.

\section{References}

[1] Adnan, S., Hoang, M., Wang, H. And Xie, Z. (2012) 'Commercial PTFE membranes for membrane Distillation application: Effect of microstructure and support material', Desalination, Vol.284, pp.297-308.

[2] Al - Amoudi, A. S. (2010) 'Factors affecting natural organic matter (NOM) and scaling fouling in NF Membranes: a review', Desalination, Vol.259, Nos.13, pp.1-10Al - 1 - Hathal

[3] Al - Anezi, A., Sharif, A. O., Sanduk, M. I. and Khan, A. R. (2012) 'Experimental Investigation of heat and mass transfer in tubular membrane distillation module for Desalination', ISRN Chemical Engineering, Vol.1, pp.1-8.

[4] Bryk, M. T. and Nigmatullin, R. R. (1994) 'Review: membrane distillation', Russian Chemical

[5] Reviews, Vol.63, No.12, pp.1047-1062.

[6] Bui, V. A., Vu, L. T. T. and Nguyen, M. H. (2010) 'Simulation and optimisation of direct contact Membrane distillation for energy efficiency', Desalination, Vol.259, Nos.1-3, pp.29-37.

[7] Burgoyne, A. And Vahdati, M. M. (2000) 'Review: direct contact membrane distillation',

[8] Separation Science and Technology, Vol.35, No.8, pp.1257-1284.

[9] Cabassud, C. And Wirth, D. (2003) 'Membrane distillation for water desalination: how to choose an Appropriate membrane?', Desalination, Vol.157, Nos.1-3, pp.307-314.

[10] Calabro, V., Drioli, E. And Matera, F. (1991) 'Membrane distillation in the textile wastewater Treatment', Desalination, Vol.83, Nos.1-3, pp.209224. 
[11] Ding, Z., Liu, L., Yu, J., Ma, R. And Yang, Z. (2008) 'Concentrating the extract of traditional Chinese medicine by direct contact membrane distillation', Journal of Membrane Science, Vol.310, Nos.1-2, pp.539-549.

[12] Dow, N., Zhang, J., Duke, M., Li, J., Gray, SR. And Ostarcevic, E. (2008) 'Membrane distillation of Brine wastes', Research report 63, Victoria University, Central Highlands Water, CRC, Water Quality Research Australia.

[13] El - Abbassi, A., Hafidi, A., García - Payo, M. C. and Khayet, M. (2009) 'Concentration of olive mill Wastewater by membrane distillation for polyphenols recovery', Desalination, Vol.245, Nos.1-3, pp.670 674.

[14] El - Bourawi, M. S., Ding, Z., Ma, R. And Khayet, M. (2006) 'Review: a framework for better Understanding membrane distillation separation process', Journal of Membrane Science, Vol.285, Nos.1-2, pp.4-29.

[15] Fane, A. G., Schofield, R. W. and Fell, C. J. D. (1987) 'The efficient use of energy in membrane Distillation', Desalination, Vol.64, pp.231-243.

[16] Findley, M. E. (1967) 'Vaporization through porous membranes', Ind. Eng. Chem. Process Des. Dev., Vol.6, No.2, pp.226-230.

[17] Fujii, Y., Kigoshi, S., Iwatani, H. And Aoyama, M. (1992) 'Selectivity and characteristics of direct Contact membrane distillation type experiment I. Permeability and selectivity through Dried hydrophobic fine porous membranes', Journal Of Membrane Science, Vol.72, No.1, pp.53-72.

[18] Garcica - Payo, M. C., Izquierdo - Gil, M. A and Fernández - Pineda, C. (2000) 'Air gap membrane Distillation of aqueous alcohol solutions', Journal of Membrane Science, Vol.169, No.1, pp.61-80.

[19] Gazagnes, L., Cerneaux, S., Persin, M., Prouzet, E. And Larbot, A. (2007) 'Desalination of Sodium chloride solutions and sea water with hydrophobic ceramic membranes', Desalination, Vol.217, Nos.1-3, pp.260-266.

[20] Summers, E. K., Arafat, H. A. and Lienhard, J. H. (2012) 'Energy efficiency comparison of singlestage membrane distillation (MD) desalination cycles in different configurations', Desalination, Vol.290, pp.54-66.

[21] Termpiyakul, P., Jiraratananon, R. And Srisurichan, S. (2005) 'Heat and mass transfer Characteristics of a direct contact membrane distillation process for desalination', Desalination, Vol.177, Nos.1-3, pp.133141.

[22] Zuo, G., Wang, R., Field, R. And Fane, A. G. (2011) 'Energy efficiency evaluation and economic Analysis of direct contact membrane distillation system using Aspen Plus', Desalination, Vol.283, pp.237-244. 